\title{
Learning Pod: A New Paradigm for Reusability of Learning Objects
}

\author{
Namdar Mogharreban and Dave Guggenheim \\ Southern Illinois University, Carbondale, IL, USA
}

\author{
namdar@cs.siu.edu; dguggen@siu.edu
}

\begin{abstract}
Learning objects have long promised dramatic savings of time and money in course and curriculum development, but they have failed to deliver the return on investment that seems a nat ural extension of their existence - reusability. Because a single hour of online instruction can take up to 300 hours to develop, reusability is the core value message offered by learning object promoters, from the earliest days to the present. Yet, after 12 years of successive evolution, learning objects are still primarily a collection of stand-alone modules that rarely interconnect outside of strictly controlled regimes, such as those imposed by corporate and military training guidelines. Among the contributing factors to this impediment are definition of a learning object, size of a learning object and aesthetics of a leaming object.

In response to this shortcoming, we propose to introduce a new entity - the learning pod. Engineered for reusability, the learning pod incorporates several modules that bring current technology to create an experientially seamless interconnection between disparate learning objects.

These modules communicate with one another to build a consistent unit of instruction that uses several learning objects depending on the requirements. Several technologies including semantic web, XSL/XML and CSS are utilized to achieve presentation cohesiveness.
\end{abstract}

Key words: Learning Object, Reusability, Learning Style, Learning Pod, XSL, XML, XHT ML

\section{Introduction}

In 1994 the term "learning objects" made its first appearance in the title of Wayne Hodgins' CedMA working group: "Learning Architectures, APIs and Leaming Objects" (Polsani, 2003). This reference is ostensibly made toward object-oriented programming, a paradigm of soft ware engineering where soft ware programs are built using modules that are interoperable, reusable, and easier to maintain than their monolithic counterparts. In a similar fashion, an academic course can be broken up into computer-mediated instructional units that possess these same qualities - portability, adaptability, reusability, and ease of maintenance.

Material published as part of this publication, either on-line or in print, is copyrighted by the Informing Science Institute. Permission to make digital or paper copy ofpart or all of these works for personal or classroomuse is granted without fee provided that the copies are not made or distributed for profit or commercial advantage AND that copies 1) bear this notice in full and 2) give the full citation on the first page. It is permissible to abstract these works so long as credit is given. To copy in all other cases orto republish or to post on a serveror to redistribute to lists requires specific permission and payment of a fee. Contact 0HPublisher@InformingScience.org to request redistribution permission.
Because a single hour of online instruction can take up to 300 hours to develop (Kapp, 2003), reusability is the core return on investment (ROI) message offered by learning object promoters, from the earliest days to the present (Churchill, 2005, 2007; Downes, 2003; du Plessis, 2005; García-Barriocanal, Sicilia, \& Lytras, 2007; Hodgins, 2000; Liber, 2005; Liu, Huang, \& Chao, 2005; Polsani, 2003; Wiley, 2000). Yet, after 
12 years of successive evolution, learning objects are still primarily a collection of stand-alone modules that rarely interconnect out side of strictly controlled regimes, such as those imposed by corporate and military training guidelines.

The lack of reusability does not stem from a dearth of technical and procedural standardization. Groups like IMS Global Learning Consortium, Inc. (IMS Global), IEEE Learning T echnology Standards Committee (LT SC), Cisco Systems (Cisco 1999), and, by extension, Griffiths, Stubbs, and Watkins (2007) have published documents that describe in detail process analysis, metadata, sequencing, learning management system portability, test and assessment, and/or interconnection. What is missing from these control structures is the conceptual and aesthet ic engineering necessary to promote visual, auditory, and kinesthetic consistency as well as interoperability at the lowest level, from learning module to learning module.

\section{Impediments to Reusability}

\section{Definition}

Several fact ors coalesce into a collective impediment to reusability. First, the definition of a learning object is devoid of a uniform structure, making the reuse of these nebulous entities difficult. Borrowing from Churchill (2007), here are some example definitions:

- Any digital or non-digital ent ity for technology-supported learning (IEEE, 2001).

- Atomic or aggregate learning resources (IMS Global, 2003)

- Any digital resource used to support learning (Wiley, 2000).

- Any digital resource used to mediate learning (Wiley \& Edwards, 2002).

- A LO can be based on an electronic text, a simulation, a Web site, a gif graphic image, a QuickT ime movie, a Java applet or any other resource that can be used in learning. (McGreal, 2004).

- A collection of $7 \pm 2$ components containing content, practice and assessment parts (Cisco Systems, 2001).

- Combined knowledge object and a strat egic object representing a mental model to be developed by a leamer through incremental elaboration (Merrill, 2000).

- Interactive digital resource illustrating one or more concepts (Cochrane, 2005).

- Interactive visual representation (Churchill, 2005).

\section{Magnitude}

Learning objects have been metaphorically described as chunks, nuggets, LEGO ${ }^{\mathrm{TM}}$ blocks, Lincoln Logs ${ }^{\mathrm{TM}}$, atoms, molecular compounds, and crystals (Hodgins \& Conner, 2000; Liber, 2005; Mejias \& Shoemaker, 2005; Wiley, 1999). Rehak and Mason, 2003 aptly describe this chaotic environment:

Different definitions abound, different uses are envisaged, and different sectors have particular reasons for pursuing their development. In this environment of uncertainty and disagreement, the various stakeholders are going off in all directions.

In what seems like a moment of resignation (or perhaps capitulation), IMS Global's 2007 annual report, “Achieving Learning Impact 2007," does not men- 
tion "reusability" once in its 65 pages that purport to offer "the latest trends in learning, technology, and standards" (IMS Global, 2007). (This report does mention "reuse" twice, the first occurrence appearing on page 50.)

\section{Aesthetic}

Another hindrance is the lack of support for separation of learning objects, page layout, and aesthet ic parameters into discrete, transferable data objects. Under the current paradigm, a page of learning objects using 10-point T imes New Roman font, excess white space, and a light blue color scheme could be married, using a SCORM-compliant interface, to one offering the visual treat of 24-point Bookman Old Style, dense paragraphs, and ochre hues and tints. This would be the aesthetic equivalent of attaching a salamanderto a rhinoceros, an unwieldy beast at best. Separating font, color, and page layout from the learning objects allows downstream instructors to extract the relevant functional information and overlay it on their aesthet ic preference.

Addressing these impediments to reusability, we propose to introduce a new ent ity - the learning pod - shown in Figure 1. Designed as an object-oriented structure with the capabilities offered by instantiation, encapsulation, inheritance, and polymorphism, the learning pod consists of learning objects and several soft ware modules - Theme Builder, Styler, Learner, and Evaluator - that drive their learner-dependent selection, positioning, and reuse. These engines, when combined with feedback mechanisms, create a structure that is highly reusable, from the entire course down to a single digital element of instruction.

\section{Acquisition Pod}

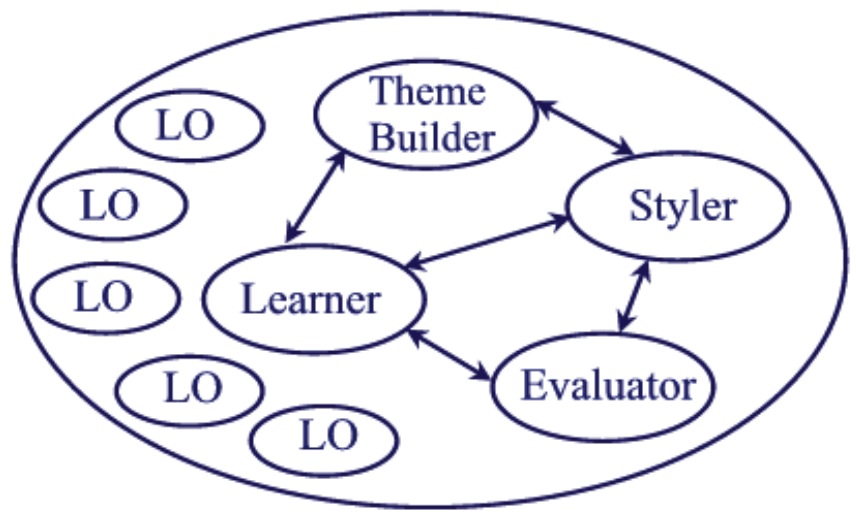

Figu re 1 -Conce ptual View of a Learning Pod

Following Bloom's taxonomy of educational objectives (Bloom, 1956), learning pods are to be developed in a series of three accretive types: acquisition, exploration, and discovery.

\section{Learning Objects and Engineered Reusability}

The difference between a learning object and a learning pod begins with the definition of a learning object itself. Rather than continue to promote definitions that encompass the continuum from discrete digital components to full-fledged aggregate coursework, we have adopted a strictly granular approach to retain the highest level of reuse. Learning objects are context-free digital elements, whether text, audio, video, animation, etc., that become leaming objects only when applied within a context of learning. The context of learning is defined by the "Theme Builder" of the leaming pod. A pod is a collect ion of learning objects connected with sound pedagogical principles by way of software engines driving metadata, sequencing, personalization, and reus- 
ability in the form of encoded functional and aesthetic information. Most importantly, the learning pod utilizes available technology, albeit state-of-the-art, to accomplish its tasks.

The engineered reusability of a learning pod begins with importing or creating learning elements in the form of digital, context-free audio, video, text, or interactive components that may be affixed to a browser-based presentation layer or web page. By remaining context-free at this level, the learning object is inherently reusable. These learning objects do have metadata, but only that which defines the structural specifications of the object instead of imposing, accidentally or otherwise, restrictions on it potential use. Following this guideline, a set of linguistic variables has been proposed as metatags.

These include:

1. Granularity - very small, 0 , to very large. Granularity refers to the amount of content a LO contains. This can be translated to the amount of resources or the bandwidth required for utilization of the object.

2. Specificity - very general, 0 , to very specific, 1 . Specificity tag denotes the applicability of a LO. Is the object of a general nature or is it specific to a single topic?

3. Cognitive Demand - On a range from 0 (low - grade school)to 1 (high - college). At what intellectual level does the object present information? (Text objects may be easily classified using the Flesch-Kincaid readability score, already available as a computer program.)

4. Prerequisite - If the specificity is higher than a nominal value, such as 0.50 , then a prerequisite may be necessary. This meta-tag varies from none, 0 , to several, 1.

The use of linguistic terms and the fuzzy set are intended to simplify the creation of a learning pod by a designer. Similarly the Styler module can take advantage of the fuzzy rules to better create a learner specific pod.

In addition to the metadata, each learning object has associated keywords, which include language of origin, copyright owner, type of object (text, audio clip, etc.), statement of purpose, and potential applications. The statement of purpose describes the content, such as a speech classified as "speech." But potential applications for that speech may include speech communications, history, management style, biography etc. Encompassing the meta-tags that allow fuzzy-logic selection and indexed keywords that promote the broadest possible use, a software engine could search, select, and place learning objects on a presentation layer using either manual or automated processes, or both.

\section{The Theme Builder Module}

The Theme Builder (Figure 2) is a collection of search criteria, metatags, design data, and keywords about the contents and structure of the unit of instruction contained within the learning pod that allow the pod to be found and instantiated. Conforming to the principles of object-oriented design, the Theme Builder presents a layer of abstraction (encapsulation) that provides external contact as the aim of a search or as the export agent forthe contents and design of the learning pod. Primarily, Theme Builder contains the overarching topic that describes the mission and content of the learning pod, appropriate grade level or background, packaged page layout, individual learning object title, type and placement, sequencing, and aesthet ic informat ion provided by the Styler. Populated with this information, the Theme Builder has enough data to export a blueprint of the baseline learning pod (prior to Learner adaptation), allowing a receiver to reconstruct the unit of coursework as a clone of the original - the essence of instantiation. 
Linking with the Learner module, Theme Builder has the potentialto contain additional generic information extracted from learning episodes (personal data removed), such as mean score by grade level, 5-number summary of scores (minimum, $1^{\text {st }}$ quartile, median, $3^{\text {rd }}$ quartile, maximum), pass/fail ratios - even student satisfaction ratings if desired. This will provide a qualitative measurement of the learning pod to the out side world for inspection prior to its reuse.

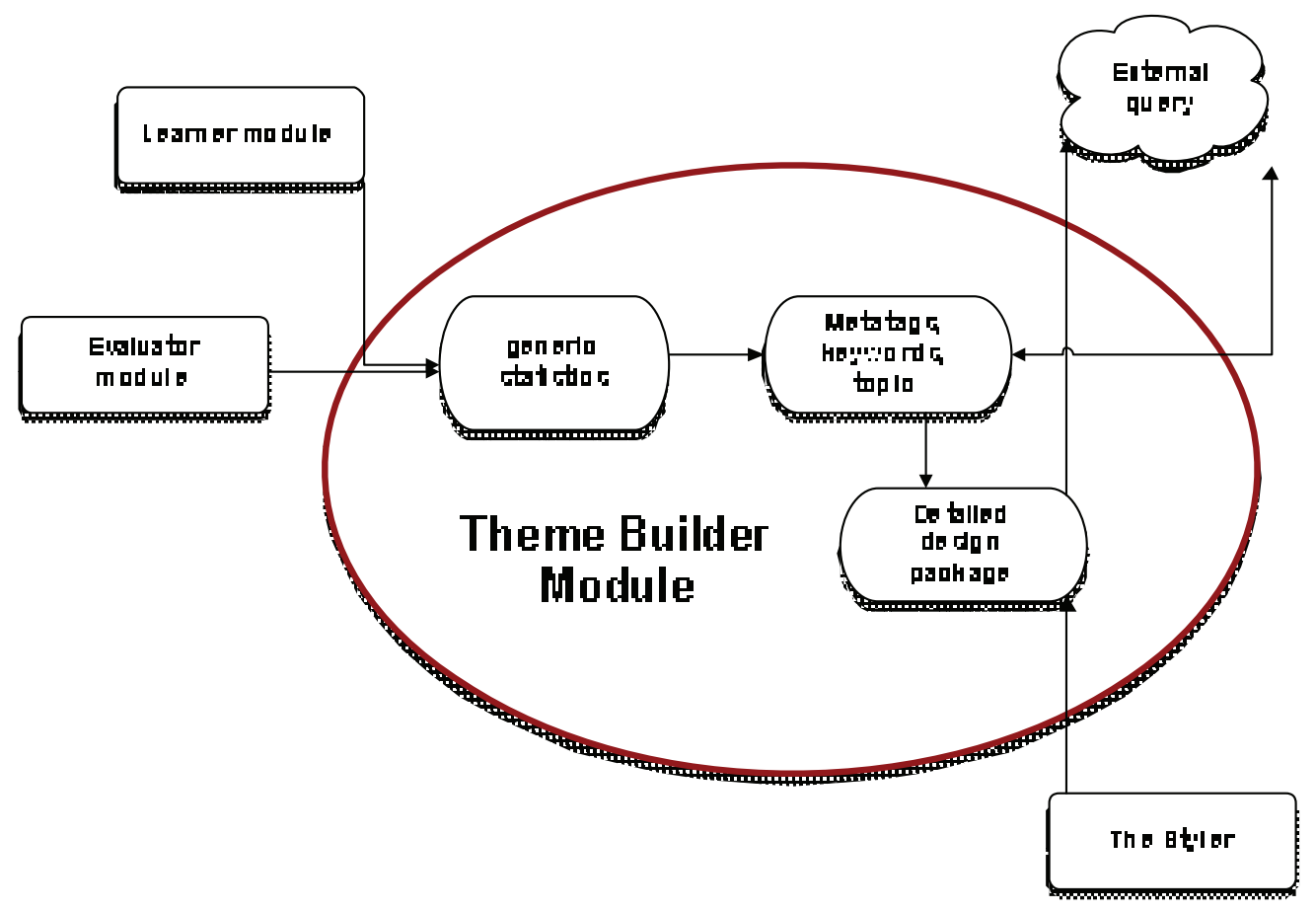

Figu re 2 - The Theme Builder module

\section{The Styler Module}

The Styler (Figure 3) is an internally-focused multi-use software engine that performs the following tasks:

- Determination of leamer's cognitive/learning style

- Learning object selection based on learner cognitive/learning style

- Presentation-layer authoring tool

- Sequencing of instructional and assessment pages

- Packaging and export of design information separate from content

Finding and selecting appropriate leaming objects for a unit of study is potentially an automated process using fuzzy-logic determination combined with keyword analysis. The instructional designer would input the desired topic and characteristics into a structured query-driven search engine designed to retrieve digital learning elements based on fuzzy-logic metatags, and the result would be the population of a local library with learning objects meet ing the criteria.

Another function of the Styler is to generate pre-assessment, instructional, and assessment pages using drag-and-drop technology via standard page layout soft ware interface. Realization of a learning pod authoring system, though, mandates that aesthetic design data, both sensory and 


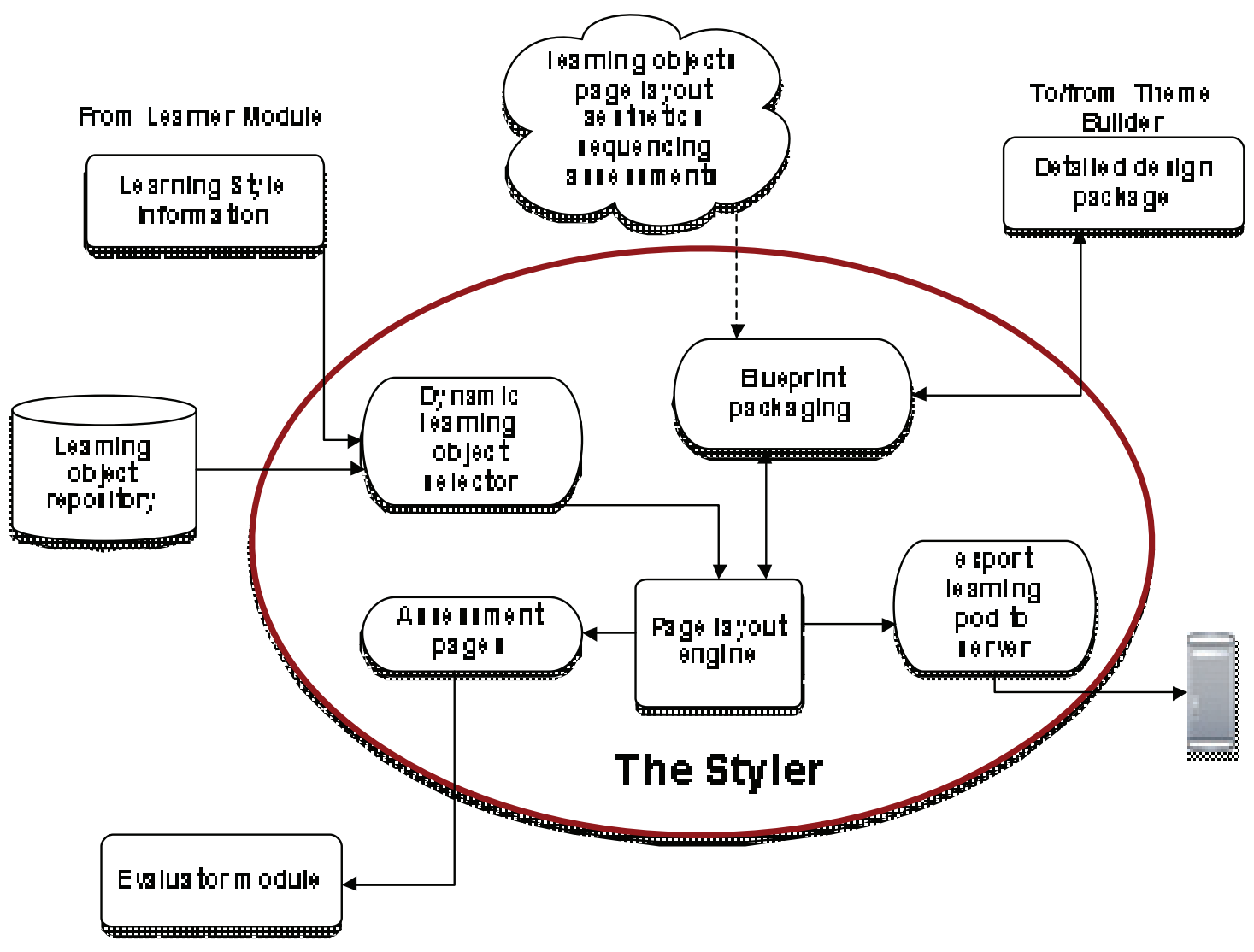

Figu re 3 - The Styler module

immersive, be encapsulated apart from the content using purpose-built style sheets. This isolation of form and function calls for a new specification linked to XSL visual design data. In addition to metadata, a lesser degree of abstraction is necessary to cat alog the aesthetics of a presentationlayer web page. Design principles such as layout, font, color schemes, frame placement, button style, white space, movement, and object relationships on a 'page' are essential aspects of sound instructional design, yet these components are not codified among the technical standards available for specific reuse. It has been suggested that each learning object developer create multiple styles using XSL/XML style sheets, in the hopes that one of those will aesthetically match a module developed by another course designer (Polsani, 2003). Rather than invite probabilistic determination in deciding whether learning objects are reusable, we propose a means of achieving compatibility between disparate leaming pages and pods that relies on the electronic exchange of stylistic attributes with both manual and aut omatic reactions. The location of learning objects on a page will be automatically generated and kept in a dat a file as standard page layout information (object meta-tags \& title and $\mathrm{x}-\mathrm{y}$ coordinates along with $\mathrm{x}$-y pixel size information). This geometric mapping, the sequence of pages, and other aesthetic information will be codified and transmitted to the Theme Builder module as the blueprint of the leaming pod. In this way, the Styler and Theme Builder modules work together to achieve encapsulation and inherit ance of the learning pod.

In addition to designing and building single or multiple pages of pre-assessment, instruction or assessment, the Styler sequences the pages using a page-sorter view according to the pedagogical principles applied by each individual instructor/designer. Sequencing may be accomplished on a page-by-page basis or by using an instructional algorithm/template such as those proposed by 
Component Display Theory (Merrill \& T witchell, 1994), Elaboration Theory (Reigeluth \& Stein 1983), Instructional Transaction Theory (Merrill, 1999), or the collect ion offered by Kaur, Dunning, Bhattacharya, and Ahmed (2005). Using web pages as the basis for the presentation layer not only offers the greatest flexibility in learning object selection (text, audio, animation, fullmotion video, interactive applets, etc.), it makes the job of sequencing using a page-sorter view rather simple. Standards, such as IMS Global's Common Cartridge Format (IMS Global, 2008) and ADL's SCORM (ADL, 2006), will find applicability only when adapting learning pods to third-party Learning Management Systems (LMS) because learning pods and their contents are inherently interchangeable, adaptable, and reusable using only the generic standards for XHT ML within HTML 4 as specified by the W3C (2002).

Beyond the baseline layout and sequence, adaptive sequencing of instructional pages, driven by an understanding of the learner's prior knowledge and skillset, is integral to the learning pod. Work done by Brusilovsky and Peylo (2003), Brusilovsky and Vassileva (2003), García-Valdez, Licea, Castillo, and Alanis (2007), and Weber and Brusilovsky (2001) establish the means by which artificial intelligence techniques may be used to define a learner-centric path through coursework.

Regardless of whether the pages are assembled ad-hoc, divined through an algorithm, or prepared using a template, a page-sorter view with color-coded page margins indicat ing basic instruction sequence, intermediate assessments, and progression thresholds will be available to the designer. Furthering the object-oriented design principle of polymorphism, imported pages or sequences of pages may be used as-is, redesigned with altered or new learning objects, and/or rearranged according to the teacher's pedagogical principles. In all cases, the imported pages will adopt the aesthetic parameters of the destination instructional program. When sequencing selection is complete, the system will generate a data file of the pages, objects, and all other visual, auditory and kinesthetic information.

Finally, the Styler has the ability to catalog what type of learning object occupies the page or portion thereof and to make dynamic substitutions or additions based on the learner's cognitive style. Several methods for capturing learning styles and using that information to drive learning object selection have been proposed (García, Amandi, Schiaffino, \& Campo, 2007; García-Valdez et al, 2007; Kaur et al., 2005; Mustaro \& Silviera, 2006; Santally \& Senteni, 2005; Wolf, 2002).

Whether the learning style is discerned from analyzing responses to a questionnaire, like the 118question survey proposed by Wolf (2002) in the iWeaver project, or if it is detected in real-time during the course of instruction by providing altemative content models to be rated by the learner and corroborated by learner responses, the relevant information from which the Styler will base its placement decisions comes from the Learner module.

\section{The Learner Module}

Information about the learner, such as grade level, prior knowledge, course histories, and learning style(s) is kept in a secure, password-protected and encrypted data file capable of being contained on a smart card. Interacting on a two-way channel with the Styler and Evaluator modules, the Learner (Figure 4) contains derived learning style data and pre-assessment test scores (so as to establish a prior knowledgebase before engaging in the main instructional unit), with the caveat that the leaming style may dynamically drive learning object selection, and prior knowledge may then drive sequencing and progression. When the student has completed a section of instruction, assessment results are returned to the Learner module from Evaluator and stored in a secure environment. When a course has been finished, a blueprint of their coursework, including learning objects, layout, sequencing, assessments and scores, is saved to the Leamer data file. Using this information, it would be possible to reconstruct a static reproduction of the exact instruction he or she received. 
With regard to learning styles, each time the learner interacts with a learning pod, available data is captured and kept in this secure environment. By maintaining a long-term history, the Learner has the ability to catalog learning styles based on topic, content, time of day, or any other available parameter with an associated value.

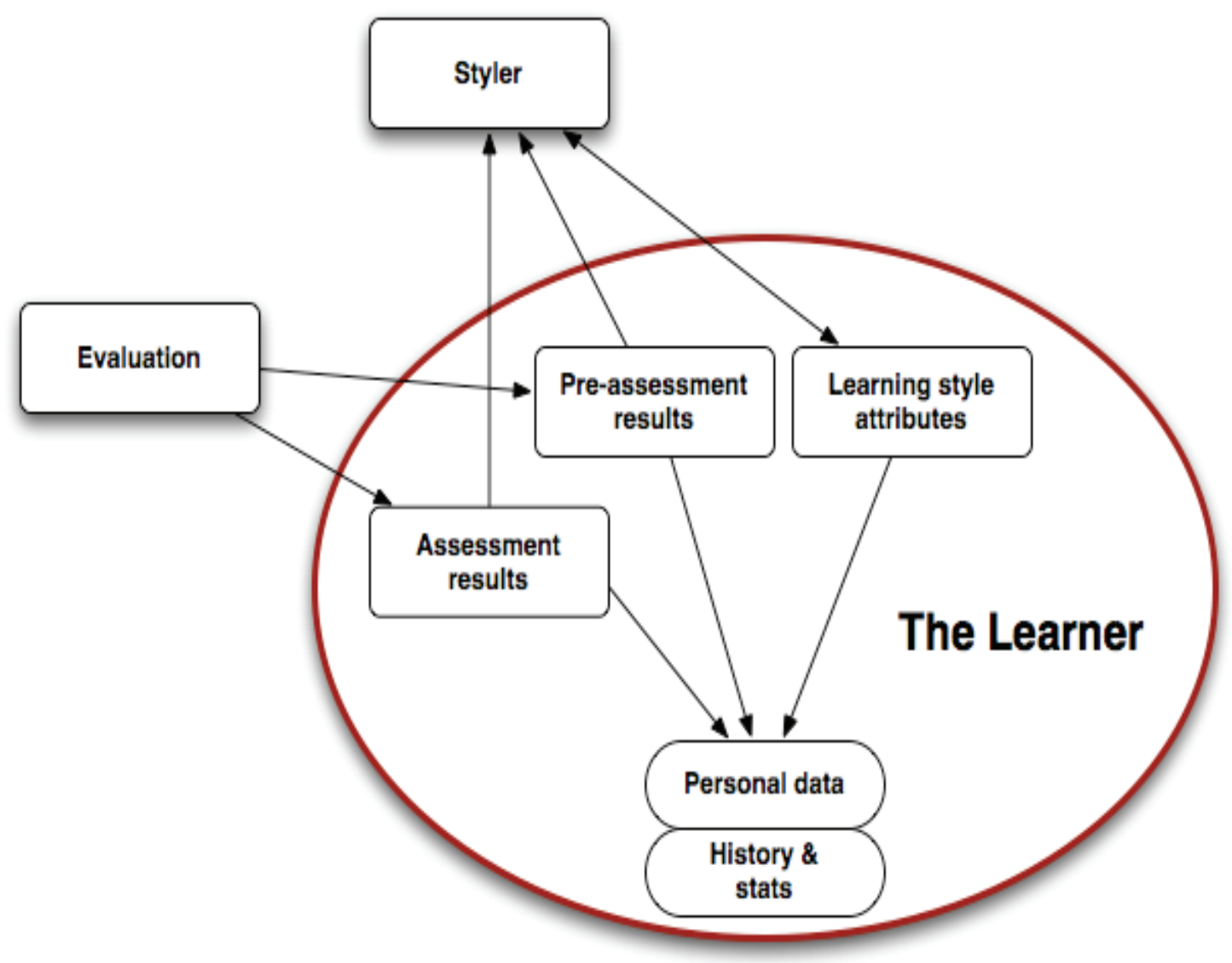

Figu re 4 - The Leamer Module

\section{Evaluator Module}

Every course of instruction must include some means of assessing the learner's performance at three general waypoints: 1) prior to engaging with the coursework to establish prior knowledge, 2) performance hurdles offered during the course of instruction, and 3) post-instruction qualification. Assessments and evaluations are conducted by the Evaluator module (Figure 5), a discrete program within the learning pod that is tightly integrated with the Styler and Leamer modules. When sequencing pages of instruction with the Styler during the design and build phase, the designer will denote those pages reserved for assessment purposes. Templates defining assessment types (multiple choice, fill-in-the-blank, matching, essay response) and any relevant learning objects are selected, placed on a page, and populated with questions, answers, and when revealed with an incorrect answer, page locations where the correct answer is discussed. 


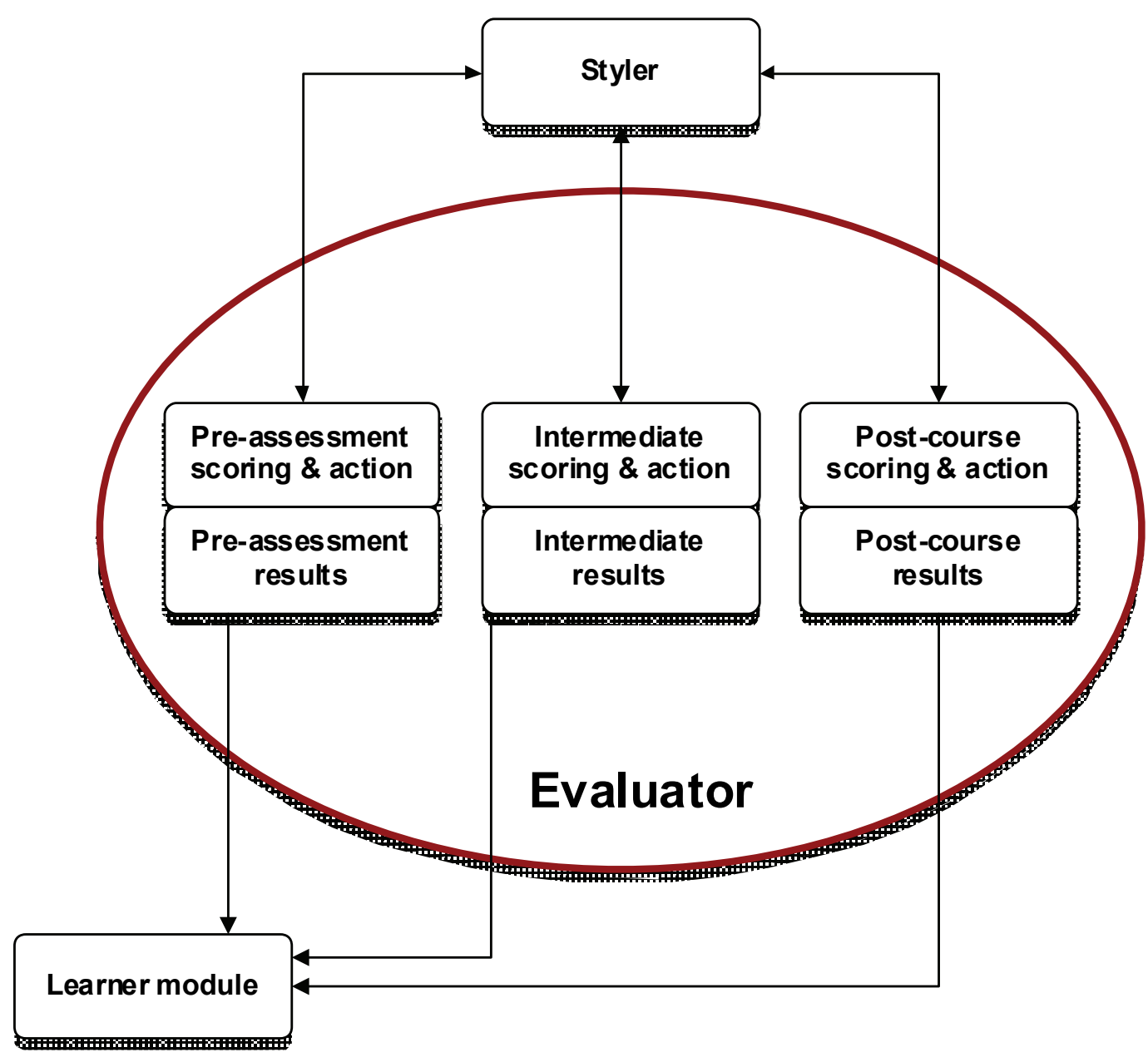

Figu re 5 - Evaluator module

Logical rules-based expressions are programmed into the Evaluat or module that instructs the Styler as to sequencing actions based on assessment results. For example:

Rule 1: If Assessment $\mathrm{A}>80 \%$ and Assessment $\mathrm{B}>=50 \%$, then unlock Page $\mathrm{X}$ (which in turn unlocks a new sectional study path).

Rule 2: If Assessment $\mathrm{A}<80 \%$ and Assessment $\mathrm{B}$ is $>=50 \%$, then return to Page $\mathrm{Y}$, but skip over the section beginning with $\mathrm{Page} Z$.

Results of assessments are provided to the Leamer dat a file for long-term secure storage and future student-learning pod interaction as prerequisite information.

Another use for assessment data is to generate scoring statistics that reflect the intended use and quality of the learning pod. Transferring generic student grade level and scoring information from the Evaluator module to the Theme Builder for statistical processing and presentation to a query response adds a valuable indicator for future reuse in various situations and groups.

\section{Learning Objects and the Semantic Web}

The World Wide Web(WWW), with all of its innovation and its requisite effect on nearly every field of human endeavor, is primarily a data-sharing model designed by humans, for humans. Web browsers are specifically engineered to display information in human-understandable form, 
and most information on the web meets that criteria. Yet, T im Berners-Lee, the founder of the WWW, envisioned something much grander, much broader, and having an effect much larger than current web technologies can deliver. He imagined a Semantic Web, a collection of repositories that could exchange information from machine to machine, in machine-understandable form. Machines could then act on this information and offload much work currently being done by humans to manage their time, resources, and interests.

Early on, learning objects promoters recognized the value of the Semantic Web, and in December 2000, Working Group 12, the metadat a working group of the IEEE Learning T echnology Standards Committee, came to an agreement with Dublin Core to harmonize learning object metadata with those specifications that will lead to the Semantic Web. Since that agreement, the IEEE LT SC WG12 website lists "to enable computer agents to aut omatically and dynamically compose personalized lessons for an individual learner" as a primary reason behind learning object metadata.

The technologies behind the Semantic Web are few, but very powerful. Extensible Markup Language (XML), XML Schema, and Resource Definition Framework (RDF) are the primary means of creating intelligent attributes and semantic meaning for every scrap of information on the WWW.

Standard Generalized Markup Language (SGML), a child of IBM's Generalized Markup Language, was creating as a means of encoding documents with machine-readable and machineshareable attributes. Because of its rigorous nature, it was primarily focused on large-scale projects in government and industry. But that power comes with a price - SGML requires a complex parser to fully implement. XML was developed by the W3C to make the parser smaller and simpler - in short, to make it more accessible for a broad range of uses. XML is now the standard means of encoding documents and information on the Web with semantic attributes.

By extension, XML Schema (XSD) allows rules to be applied to those XML-encoded documents by way of shared vocabularies. In essence, XSD creates a grammar for XML complete with a set of rules that allow the grammar to achieve complex operations. Because of XSD, computing machines can interpret XML documents and apply a set of rules to them that offload human work to that of the machine.

\section{Conclusions}

In this paper we have attempted to address one of the core issues with the failure of learning objects to live to their potential and expectations, namely reusability. The lack of reusability does not stem from a dearth of technical standardization. Groups like IMS Global Learning Consortium, Inc. (IMS Global), IEEE Learning T echnology Standards Committee, Advanced Distributed Learning Initiative (ADL), and others have published documents that describe in detail metadata, sequencing, test and assessment, and interconnection. What is missing from these control structures is the conceptual grounding and the aesthet ic rigidity necessary to promote visual, auditory, and kinesthetic consistency from learning module to learning module. When coupled with these concepts, we propose to introduce a new ent ity - the learning pod.

True hierarchal reusability - from a course to a section and from a page to a single learning object - has been designed into the learning pod. Constructed in a paradigm of object-oriented programming and using off-the-shelf technology, the learning pod applies those concepts to the field of learning objects by promoting maximum reuse without placing limitations on aesthet ic choice and academic freedom. 


\section{References}

ADL. (2006). SCORM 2004 (3rd edition). Retrieved August 30, 2007, from http://www.adlnet.gov/scorm/index.aspx

Bloom, B. S. (1956). Taxonomy of educational objectives, Handbook I: The cognitive domain. New York: David McKay.

Brusilovsky, P., \& Peylo, C. (2003). Adaptive and intelligent web-based educational systems. International Journal of Artificial Intelligence in Education. 13, 156-169. Retrieved September 11, 2007 from http://aied.inf.ed.ac.uk/

Brusilovsky, P., \& Vassileva, J. (2003). Course sequencing techniques for larg e-scale web-based edu cation. International Journal of Continuing Engineering Education and Lifelong Learning, 13(1/2).

Churchill, D. (2005). Learning object: An interactive representation and a mediating tool in a learning activity. Educational Media International, 42(4), 333-349.

Churchill, D. (2007). Towards a useful classi fication of learning objects. Education Tech Research Development, 55,479-497.

Cisco Systems. (1999). Reusable information object strategy: Definition, creation overview, and guidelines. San Jose, CA: Cisco Systems, Inc.

Cisco Systems. (2001). Reusable learning object strategy: Designing information and learning objects through concept, fact, procedure, process, and principle template. San Jose, CA: Cisco Systems, Inc.

Cochrane, T. (2005). Interactive quicktime: Developing and evaluating multimedia learning objects to enhance both face-to-face and distance e-l earning environments. Interdisciplinary Journal of Knowledge and Learning Objects, 1(1), 33-54. Retrieved from http://ijello.org/Volumel/v1p033-054Cochrane.pdf

Downes, S. (2003). Design and reusability of learning objects in an academic context: A new economy of education? USDLA Journal: A Refereed Journal of the United States Distance Learning Association, 17(1). Retrieved September 11, 2007 from http://www.usdla.org $/ \mathrm{html} /$ journal/JAN03 Issue/article01.html

du Plessis, J. (2005). Learning objects: Using language structures to understand the transition from affordance systems to intelligent systems. Interdisciplinary Journal of Knowledge and Learning Objects, 1(1), 55-67. Retrieved from http://ijello.org/Volume1/v1p055-066duPlessis.pdf

Garcí a, P., Amandi, A., Schiaffino, S., \& Campo, M. (2007). Evaluating Bayesian networks' precision for detecting students' learning styles. Computers \& Education, 49, 794-808.

García-Barriocanal, E., Sicilia, M., \& Lytras, M. (2007). Evaluating pedagogical classi fication frameworks for learning objects: A case study. Computers in Human Behavior, 23, 2641-2655.

García-Valdez, M., Licea, G., Castillo, O., \& Alanis, A. (2007). Simple sequencing and selection of learning objects using fuzzy in ference. Proceedings of the North American Fuzzy Information Processing Society, NAFIPS '07 Annual Meeting, 628-632.

Gri ffiths, J., Stubbs, G., \& Watkins, M. (2007). From course notes to granules: A guide to deriving Learning Object components. Computers in Human Behavior, 23, 2696-2720.

Hodgins, H. W. (2000). The future of learning objects. In D. A. Wiley (Ed.), The instructional use of learning objects: Online version. Retrieved August 21, 2007, from

http://reusability.org/read/chapters/hodgins.doc

Hodgins, W., \& Conner, M. (2000, Fall). Everything you ever wanted to know about learning standards but were afraid to ask. Learning in the New Economy e-Magazine (LiNE Zine. Retrieved September 11, 2007, from http://www.linezine.com/2.1/features/wheyewtkls.htm

IEEE. (2001). WG12: Learning object metadata. Retrieved September 4, 2007, from http://ltsc.ieee. org/wg12/ 
IMS Global Learning Consortium, Inc. (2003). IMS learning design information model. Retrieved October 25, 2007, from http://www.imsglobal.org/learningdesign/ldv1p0/imsld infov1p0.html

IMS Global Learning Consortium, Inc. (2007). Achieving learning impact 2007. Retrieved October 25, 2007, from: http://www.imsglobal.org/learningimpact2007/LI2007report.pdf

IMS Global Learning Consortium, Inc. (2008). IMS common cartridge working group. Retrieved February 25, 2008, from http://www.imsglobal.org/commoncartridge.html

Kapp, K. M. (2003). How long does it take? Estimation methods for developing e-learning. ASTD Learning Circuits. Retrieved November 6, 2007 from http://www.learningcircuits.org $/ 2003 / \mathrm{jul} 2003 / \mathrm{kapp} . \mathrm{htm}$

Kaur, A., Dunning, J., Bhattacharya, S., \& Ahmed, A. (2005). Re-purposeable learning objects based on teaching and learning styles. Encyclopedia of multimedia and technology. London, Melbourne, New York: Idea Group Publishing. 882-887. Retrieved October 20, 2007 from www.indiana. edu/ geosci/people/faculty/dunning/pdfencyc.pdf

Liber, O. (2005). Learning objects: Conditions for viability. Journal of Computer Assisted Learning, 21, 366-373.

Liu, J., Huang, B., \& Chao, M. (2005). The design of learning object authoring tool based on SCORM. Proceedings of the Fifth IEEE International Conference on Advanced Learning Technologies. Retrieved August 30, 2007 from http://ieeexplore.ieee.org/iel5/10084/32317/01508815.pdf? arnumber $=1508815$

McGreal, R. (2004). Learning objects: a practical definition. International Journal of Instructional Technology and Distance Learning, 1(9), 21-32.

Mejias, U. A., \& Shoemaker, D. (2005). Learning molecules model. Learning Circuits, May 2005. Virginia: American Society for Training \& Development. Retrieved November 6, 2007 from http://www.learningcircuits.org/2005/may2005/shoemaker.htm

Merrill, M. D. (1999). Instructional transaction theory (ITT): Instructional design based on knowledge objects. In C. M. Reigeluth (Ed.), Instructional-design theories and models: A new paradigm of instructional theory (pp. 397- 424).

Merrill, M. D. (2000). Knowledge objects and mental models. In D. A. Wiley (Ed.), The instructional use of learning objects. Retrieved August 21, 2007 from http://reusability.org/read/chapters/merrill.doc

Merrill, M. D. \& Twitchell, D. G. (Eds.). (1994). Instructional design theory. Englewood Cliffs, NJ: Educational Technology Publications.

Mustaro, P. N., \& Silviera, I. F. (2006). Learning objects: Adaptive retrieval through learning styles. Interdisciplinary Journal of Knowledge and Learning Objects, 2, 35-46. Retrieved from http://ijello.org/Volume2/v2p035-046Mustaro.pdf

Polsani, P. R. (2003). Use and abuse of reus able learning objects. Journal of Digital Information, 3(4), Article No. 164. Retrieved August 21, 2007, from http://jodi.tamu.edu/Articles/v03/i04/Polsani/

Rehak, D., \& Mason, R. (2003). Keeping the learning in learning objects. In A. Littlejohn (Ed.), Reusing online resources: A sustainable approach to elearning. London: Kogan Page.

Reigeluth, C. M., \& Stein, F. S. (1983). The elaboration theory of instruction. In C. M. Reigeluth (Ed.), Instructional-design theories and models: An overview of their current status (Vol. 1). Hillsdale, NJ: Lawrence Erlbaum Associates.

Santally, M. I, \& Senteni, A. (2005). A learning object approach to personalized web-bas ed instruction. European Journal of Distance Learning (EuroDL). Retrieved October 20, 2007 from http://www.eurodl.org/materials/contrib/2005/Santally.htm

W3C. (2002). XHTML 1.0 The extensible hypertext markup language (2nd ed.). A Reformulation of HTML 4 in XML 1.0. W3C Recommendation 26 January 2000, revised 1 August 2002. Retrieved October 20, 2007 from http://www.w3.org/TR/xhtml1/ 
Weber, G., \& Brusilovsky, P. (2001). ELM-ART: An adaptive versatile system for web-bas ed instruction. International Journal of Artificial Intelligence in Education, 12, 351-384.

Wiley, D. A. (1999). The post-LEGO learning object. Retrieved September 6, 2007, from http://wiley.byu.edu/post-lego/post-lego.pdf

Wiley, D. A. (2000). Connecting learning objects to instructional design theory: A definition, a metaphor, and a taxonomy. In D. A. Wiley (Ed.), The instructional use of learning objects. Retrieved August 21, 2007, from http://reusability.org/read/chapters/wiley.doc

Wiley, D., \& Edwards, E. (2002). Online self-organizing social systems: The decentralized future of online learning. Retrieved October 25, 2007 from http://wiley.ed.usu.edu/docs/ososs.pdf

Wolf, C. (2002). iW eaver: Towards an interactive web-based adaptive learning environment to address individual learning styles. European Journal of Distance Learning (EuroDL). Retrieved October 10, 2007 from http://www.eurodl.org/materials/contrib/2002/2HTML/iWeaver

\section{Biographies}

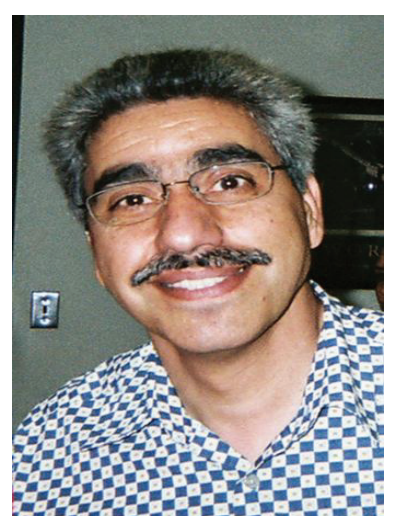

Dr. Nam dar Mogharre ban received his $\mathrm{PhD}$ in Computer Based Education in 1989. Since then he has been involved in various aspects of teaching and training in information systems and technology. Currently he is an associate professor at Southern Illinois University in the Department of Computer Science. The focus of his research has been end user computing, computing in special population, intelligent tut oring systems and data analysis. Heteaches courses in Information Systems Design, Human and Computer Interface as well as programming languages.

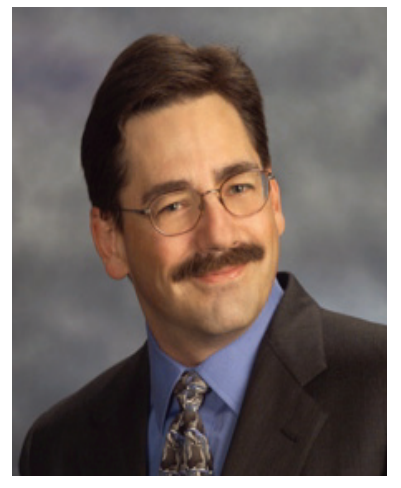

David Guggenheim. Prior to returning to a university setting and engaging in learning objects research, Dave Guggenheim was responsible for overall product vision, strategic product planning, market-driven product development, and the resulting launch and sale of a broad range of soft ware products directed toward the telecommunications industry. Most recently, as vice president of global marketing and product management, he oversaw worldwide market ing and product management functions for Ushacomm, an Indian provider of operations support systems, with headquarters in London and Kolkata. Dave has over 20 years of industry experience, including achievements in product development, product marketing, market entry, and global software product launches, which have resulted in awards for technical innovation and overall product excellence. 